\title{
NOISE POLLUTION AND ITS EFFECT ON WORKERS, PATIENTS, AND VISITORS IN SOME HOSPITALS AT DOHUK GOVERNORATE
}

\author{
SHIREEN H. RAMADHAN ${ }^{*}$ and YALDZ M.HAIDER \\ Dept .of Physics, Faculty of Science, University of Zakho, Kurdistan Region-Iraq
}

(Received: July 2, 2017 ; Accepted for Publication: January 4, 2018)

\begin{abstract}
High levels of noise may affect on patient care ,medical care workers and activity of medical educations .Three hospitals at Dohuk Governorate, two of them public hospitals (Zakho general hospital and Azady hospital) with one Private hospital (Jiyan hospital) were chosen as a sample for this study. This study aimed to identify noise levels of pollution, frequency and amplitude in these hospitals and study the effects of noise pollution on the physiological and psychological reactions and discomfort response of medical care staff, patients, workers and visitors in these hospitals. Sound levels were recorded in three hospitals using an electronically sound level meter.

The results show that the mean of the high levels of noise and frequency in Zakho General hospital are 64.683 $\mathrm{dBA}$ and $1.749 \times 10^{3} \mathrm{~Hz}$ in waiting hall in the morning and the low level are $50.033 \mathrm{dBA}$ and $1.011 \times 10^{3} \mathrm{~Hz}$ in the medical ward for female in the evening while in Azadi hospital are $59.811 \mathrm{~dB}(\mathrm{~A})$ and $1.635 \times 10^{3} \mathrm{~Hz}$ in nurse station room in the morning and the lowest are $50.838 \mathrm{dBA}$ and $0.696 \times 10^{3} \mathrm{~Hz}$ in the medical ward for male in the evening and in Jiyan hospital are $62.966 \mathrm{~dB}(\mathrm{~A})$ and $1.492 \times 10^{3} \mathrm{~Hz}$ in reception in the evening and the lowest are $49.594 \mathrm{dBA}$ and $0.770 \times 10^{3} \mathrm{~Hz}$ in doctors room at morning.

The noise pollution in Dohuk Governate greatly exceeded the world Health Organization (WHO) 30-40 dB (A) standard levels for hospitals. It concludes that the major source of noise inside and outside the wards were chats of visitors or patient's family members , patients moaning or crying, ward cleaning staff, building structure.....etc.
\end{abstract}

\section{INTRODUCTION}

T oise pollution can be defined as a type of which may poses a threat to a person's health and negatively affect people's auditory health perception, and causes physical and psychological balance damage $[1,2]$.

A hospital must a quiet atmosphere and calm environment for patients by providing a conductive material recovery to the regulatory environment and culture that supports patients and families through the pressures of the sickness, medical visit and healing process. To achieve these, the hospital management must determine the internal and external noise factors and source. Hospitals must also measure and reduce noise in the patient's room with specific levels of compliance [3]. Environmental noise in hospitals has been subjects of many medical researchers. The Environmental Protection Agency recommendation focuses on the fact that noise levels in the hospital must not exceed $45 \mathrm{~dB}(\mathrm{~A})$ during the day and $35 \mathrm{~dB}(\mathrm{~A})$ at night [4].While the International Noise Council and the World Health Organization (WHO) recommends that noise levels in hospital areas should be $35-40 \mathrm{~dB}(\mathrm{~A})$ in the daytime and $30-40$ $\mathrm{dB}(\mathrm{A})$ in the evening $[5,6]$.

There are many previous studies on the same topic done in different countries . Humam G. AlZubeer et all ,(2013), studies Noise Pollution in Mosul Medical City Center Teaching Hospitals, They concluded the noise pollution in Mosul Medical City center greatly exceeded the WHO guideline level for hospitals [7].

Abdel-Nasser Ismail Salameh, studied the effects of occupational noise exposure on blood pressure, pulse rate, and hearing threshold levels of workers in selected industrial plants in Jenin city, Palestine, he concludes that high levels of noise pollution can affect adversely the blood pressure (systolic and diastolic), pulse rate, and hearing threshold levels [8].

Juang D. F. et al,(2010), founds that the average sound levels recorded at three hospitals during the day at three different time period (morning, afternoon, and evening) ranging between 56.2 and 64.9 bear, $50.6-65.4$ bear and 50.3 - 65.7 respectively during their studies under the title (effect of noise pollution on medical care 
workers and patients in hospitals in Taiwan) and they found that these values were higher than the requirement environmental noise of the daytime $50-\mathrm{dB}$ in Taiwan [9].

Timothy Hsu et al, (2012), studies noise pollution in hospitals and its impact on patients, they found that the negative effects of noise on patients [10].

\section{MATERIAL AND METHODS \\ 1. Sampling:}

In this Study Three hospitals were used as a case study in Dohuk city ,Kurdistan - iraq , two of them are Governorate hospital (Zakho General Hospital, and Azady Teaching Hospital) with one Private Hospital (Jiyan hospital).

\subsection{Zakho General Hospital (Hospital A):}

Zakho General Hospital (200 beds), located in Bidar residential quarter opened year 2012.Consists of ( 82 beds) for patients, ( 20 beds) emergency and ( 98 beds) separate rooms, doctors almost (20 rooms) for the reception of patients . Twelve showroom operations, including halls for emergency operations and hall of burns and at intensive care and catheters, delivery and premature, with the total artificial at general surgery, and women's sections, the rays. Receives about 200 patients almost.

\subsection{Azadi Teaching Hospital (ATH) (Hospital B):}

ATH it is the only public hospital placed in Duhok city. It has been built in 1984 by Marubeni Japanese Company. The overall area is about $45000 \mathrm{~m}^{2}$ but only $8000 \mathrm{~m}^{2}$ used for hospital building .It consists of 8 floors with several accessories surrounding the hospital and the total number of beds are 490 which are separated differently on each floor. In addition, the number of the staff is about 1288.In sept 2015 the number of doctors was 373and 915 are other staff. The average numbers of daily client are 750 cases.

\subsection{Jiyan Hospital (Hospital C):}

Jian hospital located in Abbasia. The area of the hospital is $1300 \mathrm{~m}^{2}$, It is opened in 2006 which consists of two floors, The first floor consists of $(7$ beds) for patients, doctors and nurses. Almost (5 rooms) for the reception of patients and (1 room) for operation .The second floor consists of outpatient doctors.

\section{Measured Location:}

In each hospital, several sites were chosen for sound level and frequency measurement. The sites include children's ward, female ward (1) at emergency, female ward (2) at emergency, male ward at emergency, reception, waiting hall, $\mathrm{x}$-ray, male's ward, female's ward, surgical department for male, surgical department for female, hall(1), hall (2), hall(3), workers room, Nurse station room 1(N.S. room), nurse station room 2 (N.S. room 2), main room for nurses (M. room) cardiovascular ward for male, cardiovascular ward for female, oncology ward, doctors room, and lab. The device of the measurement was in the middle of the corridor at one meter high above the ground surface and half meter away from the wall for sound level and Frequency measurements were also taken at the same time.

\section{Measuring the sound level and record sound}

This study measured the sound levels and record sound in all three hospitals at three time periods during the day. The first measurement was in the morning between (9:00-11:00 a.m.), the second measurement is in the afternoon between (1:00-3:00 p.m.), and the third measurement is at evening between (6:00-8:00 p.m.). The average was recorded from the three measurements of each time period, the gotten averaged values were used for further analysis.

\section{Measuring instrument:}

An Electronically Sound Level Meter used to record sound level in all hospitals. This equipment were made to meet the requirement of health, sound quality control in various environments, and industrial safety offices. Another instrument was used to record the sound (type: ws-331m) which its supports playback of music files in MP3 and WMA formats have been used in this study. The sound files that were recorded in each hospital have been analyzed by using math lab programs to calculate the minimum and maximum frequencies and amplitudes in each location in the three hospitals.

\section{RESULTS AND DISCUSSION \\ 4.1. Sound Levels results}

Hospitals in Dohuk governorate are very noisy. The noise levels in majority hospitals have exceed recommended standard levels in hospitals. High ambient noise levels as well as extreme noise levels in hospitals have serious effects on the hospital staff, patients, and visitors.

\section{Hospital (A)}

The results for the mean equivalent noise level $\mathrm{L}_{\mathrm{eq}} \mathrm{dB}(\mathrm{A})$, Standard deviation for individual wards (children's ward, nurse station room (1), nurse station room (2), waiting hall, male's ward, female's ward, surgical department for male, surgical department for female, workers room, hall(1), and hall( 2)) during the measurement periods are shown in figure (1), the highest mean 
equivalent noise level $\mathrm{L}_{\mathrm{eq}} 64.7 \mathrm{~dB}(\mathrm{~A})$ during the testing time which were recorded in waiting hall and the minimum mean equivalent noise level is $50.0 \mathrm{~dB}(\mathrm{~A})$ in the medical ward for female. The higher noise levels found at waiting hall is due to the visitors and patients present who have operations and other diseases that making crowd in this place. The lowest level was observed on the medical ward for female because hospital (A) applies new system that is each patient has their own room.

\section{Hospital (B)}

The results of the mean equivalent noise level $\mathrm{L}_{\mathrm{eq}} \mathrm{dB}(\mathrm{A})$, standard deviation for individual wards (nursing station room, waiting hall, , wards for male, wards for female, surgical department for male, surgical department for female, cardiovascular ward for male, cardiovascular ward for female, and oncology ward during the measurement periods are shown in figure (1), the highest equivalent noise level $\mathrm{L}_{\mathrm{eq}}$ was $59.8 \mathrm{~dB}$ (A) during time period were measured in nursing station room and the lowest mean was $50.8 \mathrm{~dB}(\mathrm{~A})$ on the wards for the male. The female's conversation, nurse's activities and ward cleaning staff might have contributed to the recorded noise level on nurse station room. Another reason for the high levels of noise in nurse station room was related to the fact that these nurses are busy all the time. The minimum noise level were found in the ward for male in the evening which was due to fewer visitors and the decrease of general activity at this time.

\section{Hospital (c):}

The results of the mean equivalent noise level $\mathrm{L}_{\mathrm{eq}} \mathrm{dB}(\mathrm{A})$, standard deviation for individual wards (main room for nurses, nursing station room (1 and 2), waiting hall, reception, waiting hall, doctors room, and lab ) during the measurement periods are shown in figure(1), the highest mean equivalent noise level $\mathrm{L}_{\mathrm{eq}}$ was $62.9 \mathrm{~dB}$ (A) during time interval for measurements were found in reception and the minimum mean was $49.5 \mathrm{~dB}(\mathrm{~A})$ in the doctors room. The highest level of noise was found at the reception part because this area received all visitors of the hospital and the sound level of TV was high. The lowest levels observed in the doctors room because this is private hospital, so the numbers of visitors were lowest during the morning comparing to the evening.

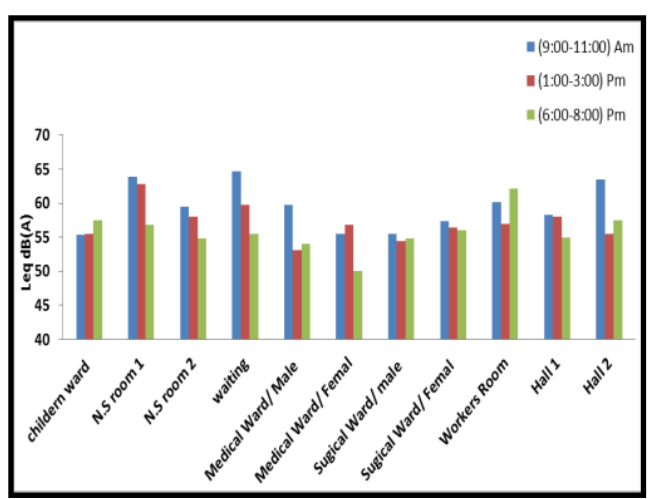

Hospital (A)

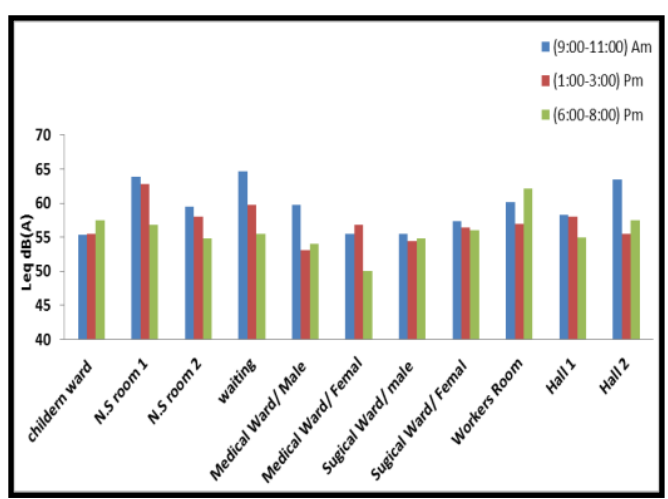

Hospital ( B )

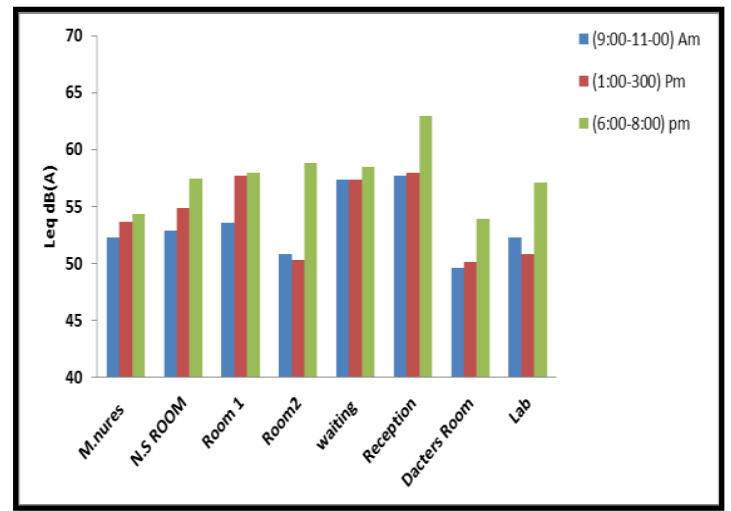

Hospital (C)

Fig (1):- equivalent and associated standard deviation $\mathrm{dB}(\mathrm{A})$ of noise level on ward and other places during the study period in hospitals 


\subsection{Comparison Sound level in Three Hospitals}

There are two main reasons why these hospitals are noisy. First, there are many medical equipment that become noise sources. Second, the building structure (surfaces, walls, floor, and ceiling) doesn't have sound isolation and its more sound reflecting rather than sound absorbing. The noise is different from hospital to another and different from time to time as shown in figure (2), it is observed that the loudest time is in the morning at hospital (A) $59.392 \mathrm{~dB}(\mathrm{~A})$ which is high according to world Health Organization (WHO). The first reason is that in the advisory hospital, the morning period is the best time that provides all requirements for patients including $\mathrm{X}$ ray, examinations, analyzes,...etc. The second reason is that big operations are being in the morning only, which accompanies the busiest for people with patients. Third reason is at the morning in addition to patients, patients visiting hospital for treatment, also high turnover and talks of visitors overcrowding on wards during the morning hours are the main reason to the recorded noise levels. However, traffic and ward activities, mostly visitors visiting patients who are in the hospital during the afternoon hours are additional source of the increased noise levels at this time of the day.

The lowest time is in the morning at hospital (C) $53.303 \mathrm{~dB}(\mathrm{~A})$ because the lowest levels observed in the doctors room because this is private hospital. So the numbers of visitors were lowest during the morning comparing to the evening.

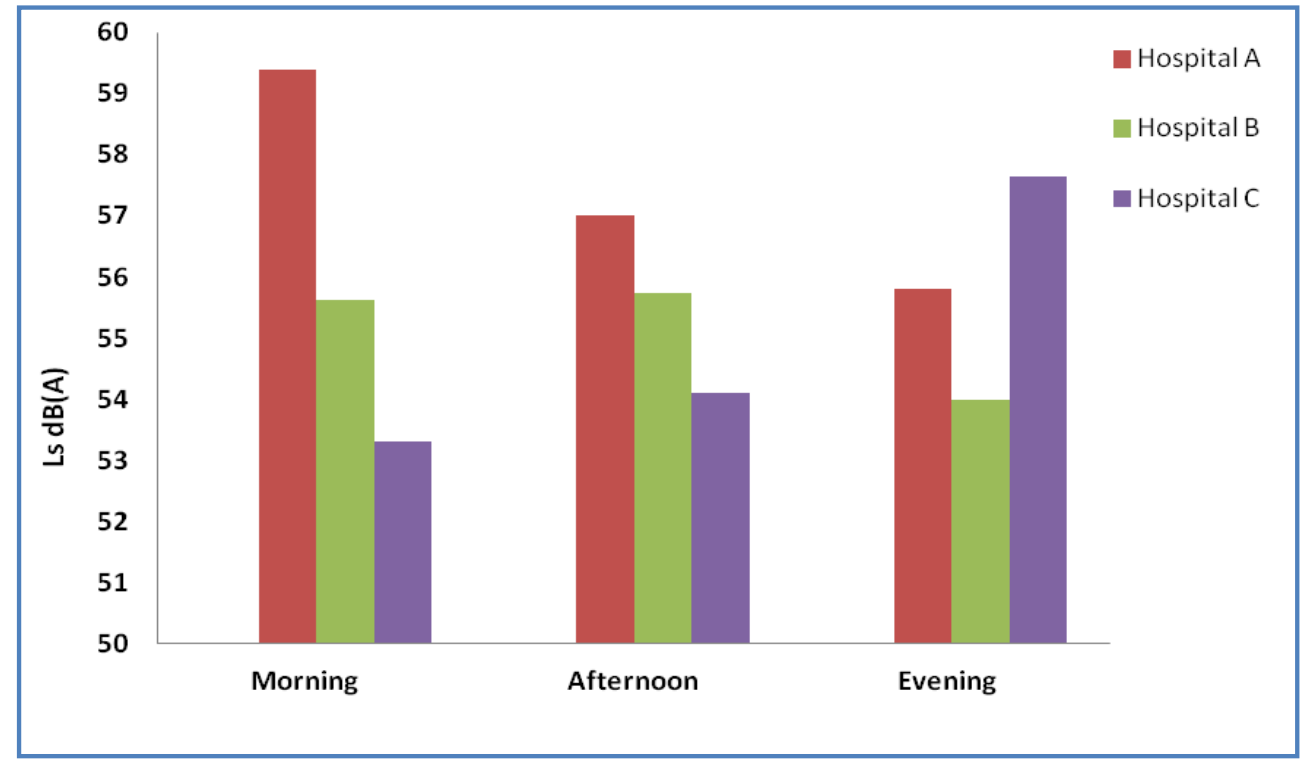

\subsection{Frequency measurement:}

Frequency (f):The number of times per second that the wave passes from a period of compression through a period of rarefaction and starts another period of compression. It is expressed a number of cycles per unit time. The SI unit of frequency is the hertz $(\mathrm{Hz})$. The range of frequencies that can be heard by the healthiest human ears is between $20 \mathrm{~Hz}$ and $20,000 \mathrm{~Hz}(20 \mathrm{kHz})$. Frequencies are heard as the pitch of sound. High pitched sounds make high frequencies; low pitched sounds make low frequencies [11].

The results of the mean frequency in three hospitals for individual wards during the measurement periods are shown in figure (3), the highest mean frequency in hospital (A) is $\left(1.749 \times 10^{3} \mathrm{~Hz}\right)$ during time interval for measurements were recorded in waiting hall and the minimum mean frequency $\left(1.011 \times 10^{3} \mathrm{~Hz}\right)$ on the medical ward for female.

The high frequency observed at the waiting hall were due to high noise level in waiting hall and lowest frequency observed at the medical ward for female because of the lowest noise level in medical ward for female. In Hospital (B), the highest mean frequency $\left(1.635 \times 10^{3} \mathrm{~Hz}\right)$ during time period for measurements were found in nursing station room and the lowest mean frequency $\left(0.696 \times 10^{3} \mathrm{~Hz}\right)$ on the medical ward for male. The high frequency observed at the nursing 
station room were due to the high noise level in nursing station room and lowest frequency observed on the medical ward for male because of the lowest noise level in medical ward for male, while in Hospital $(\mathrm{C})$, the highest mean frequency $\left(1.492 \times 10^{3} \mathrm{~Hz}\right)$ were recorded in reception and the lowest mean frequency $\left(0.770 \times 10^{3} \mathrm{~Hz}\right)$ in doctor's room. The high frequency observed on the reception were due to the high noise level in reception and lowest frequency observed on the doctor's room because of the lowest noise level in doctor's

room.

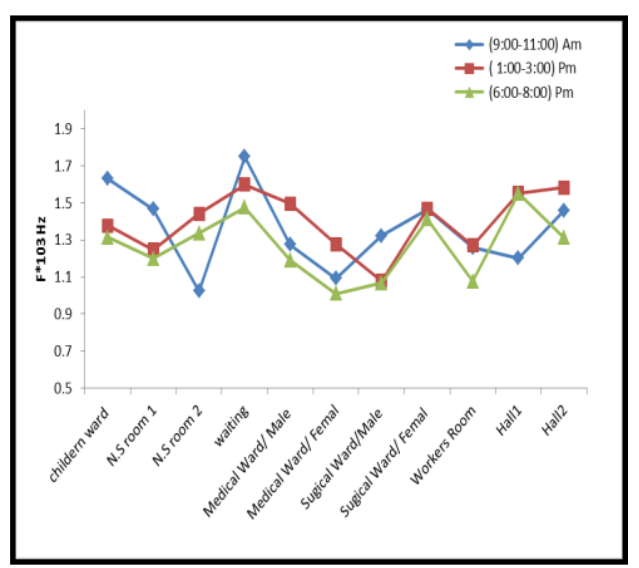

Hospital (A)

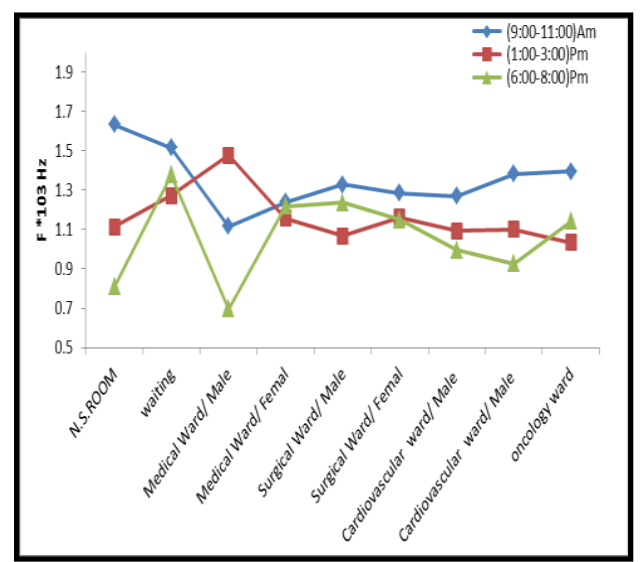

Hospital (B)

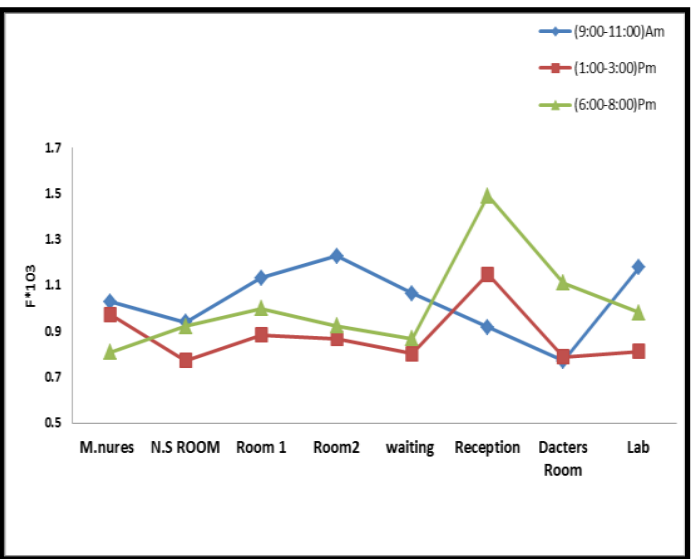

Hospital (C)

Fig (3):- Mean of frequency on other place during the study period in hospitals

\section{CONCLUSION}

This study concludes that :

1- The average sound level noises and frequencies measured in three selected hospitals (A,B, and C) for this study were higher than the recommended World Health Organization 30-40dB(A) standard levels for hospitals.
2- High noise level observed in different places depending on the hospital work, place of hospital and the number of patients who visited those hospitals, as well as hospital administration. It is important to know how they can control the quiet in the hospital and maintain patient comfort so the following points show the comparison between 
the high noise levels that occurs in three hospitals that have been taken in this study:

a) Visitors and patients who have operations and other diseases that cause crowd in waiting hall is found to be one of high noise levels at Zakho general hospital.

b) In Azady hospital and also called Azady educational hospital, the female's conversation, nurse's activities and ward cleaning staff might have contributed to the recorded noise level in nurse station room. Another reason for the high levels of noise in nurse station room was related to the fact that these nurses are busy all the time.

c) The highest level of noise was found in Jiyan hospital which is private hospital and it was at the reception part because this area receives all visitors to the hospital and the sound level of TV is high.

d) The high frequency observed at the same places were had high noise level in all hospitals that had been token for this study.

e) According to the time period it was observed that the loudest time is in the morning at hospital (A) $59.392 \mathrm{~dB}$ (A) which is high according to World Health Organization (WHO). The lowest time is in the morning at hospital (C) $53.303 \mathrm{~dB}$ (A)

3- The non sound-isolated surfaces of hospitals cause noise to spread distances, traveling down corridors then into patient rooms, and affecting patients and staff over larger areas. As well as typical cause sounds to echo, overlap, and have long reverberation times.

4- In Three hospitals (A,B , and C); It seems to contribute to noisy noise levels in hospitals come from visitors or patient's family members talks, patients moaning or crying, opening or closing doors, crying children and the activities of mothers inside the ward. In addition, multibedroom ward all have shown that most of the noise stems from the presence of another patient.

\section{Recommendation}

Due to the increasing high levels of noise in health centers and hospitals, the study of noise pollution in these facilities became one of the interesting issues in modern era. All applied standards of noise in have shown that the problem of noise pollution in health facilities and hospitals is a global problem. This study supports some of recommendations to reduce the noise levels in hospitals, these recommendations are:
1. The ministry of health of Kurdistan - Iraq region should consider and encourage researchers to conduct wider and more comprehensive researches to deal with this issue.

2. The hospitals' management should improve visiting programs of patients' families to patients in order to minimize the main sources of noise pollution, such as visitors' talk or patient's families, "patients moaning or crying", and "doors opening or closing".

3. Hospitals' management should deploy banners demanding visitors and employees to limit their voice to the maximum extent possible and to reduce the sound level of their phones bells and speakers.

4. Restricting visits, visiting time and number of visitors in hospital.

5. Restricting the escort of each patient by only one person.

6. Using soft flooring and sound insulating material in buildings, on the doors and windows should be taking inconsideration.

7. All employees in hospitals should wear special shoes that prevent noise.

8. Prevent exchange of visits between the employees inside hospital departments.

9. Organizing training times of students in Governmental educational hospitals

Due to the increasing high levels of noise in health centers and hospitals, the study of noise pollution in these facilities became one of the interesting issues in modern era. All applied standards of noise have shown that the noise pollution in health facilities and hospitals is a global problem. This study supports some of recommendations or suggestions to reduce the noise levels in hospitals, these recommendations are:

1. The ministry of health of Kurdistan - Iraq region should consider and encourage researchers to conduct wider and more comprehensive researches to deal with this issue.

2. The hospitals' management should improve visiting programs of patients' families to patients in order to minimize the main sources of noise pollution, such as visitors or patient's families talks and doors opening or closing.

3. Hospitals' management should deploy banners demanding visitors and employees to limit their voice to the maximum extent possible and to reduce the sound level of their phones bells and speakers.

4. Restricting visits, visiting time and number of visitors in hospital. 
5. Restricting the escort of each patient by only one person.

6. Using soft flooring and insulation materials sound in buildings, on the doors and windows.

7. All employees in hospitals should wear special shoes that prevent noise.

8. Organizing the time of training for students in governmental educational hospitals.

\section{REFERENCES}

- Singh ,Narendra and Davar, S. C. (2004), "Noise Pollution, Sources, Effects and Control". J. Hum. Ecol, Vol .16, No.3: PP 181.

- Durduran, S. Savas, Kunt Fatma and Dursun Sukru (2008), " Noise Pollution Mapping in Konya (Turkey) City Hospitals Using GIS Model”.J. Int. Environmental Application and Science ,Vol .3, No. 5: pp. 415.

- Vinodhkumaradithyaa A. , Srinivasan M. , Ananthalakshmi I. , (2008), "Noise levels in a tertiary care hospital". Noise \& Health, Vol .10, No. 38: pp 11-13.

- Kléber P. A. , Loraine L. A. , Rodrigo P. S. , and Ione M. M. , (2016), "Noise level measurement and its effects on hospital employees based on complaint reports". Rev. CEFAC vol.18 no.6 São Paulo, ISSN 1982-0216

- Mujtaba B., Muhammad A., Saddam A. A., Uzma Kh. , and Hina Z., (2017),"Noise Pollution in the hospital environment of a developing country: A case study of Lahore (Pakistan), Archives of Environmental and Occupational
Health •

https://doi.org/10.1080/19338244.2017.1371106

- World Health Organization (2010), WHO Guidelines for Community Noise, "http://whqlibdoc. who.int/hq/2010".

- ] Humam G. Al-Zubeera, Asma A. Al-Jawadia Raghad A. Al-Joomard

(2013), "Noise Pollution in Mosul Medical City Center Teaching Hospitals", Ann Coll Med Mosul,39 (1):32.

- Salameh ,Abdel Nasser Ismail (2005), “studied Effects of Occupational Noise Exposure on Blood Pressure, Pulse Rate, and Hearing Threshold Levels of Workers in Selected Industrial Plants in Jenin City, Palestine", AnNajah National University Faculty of Graduate Studies, Master thesis: pp50.

- Juang D. F, Lee C. H., Yang. T, and Chang M. C (2010),"Noise pollution and its effects on medical care workers and patients in hospitals".Int. J. Environ. Sci. Tech; 7 (4):pp714.

- Timothy Hsu, Erica Ryherd, Kerstin Persson Waye, and Jeremy Ackerman,(2012)," Noise Pollution in Hospitals: Impact on Patients",

19(7):307-308]

- Al-Zahrani Abdulaziz (2007) ,"study of noise pollution during hajj season $1427 \mathrm{H}$ ".Umm AlQura University College of Engineering and Islamic Architecture, Master Thesis ,pp 21.

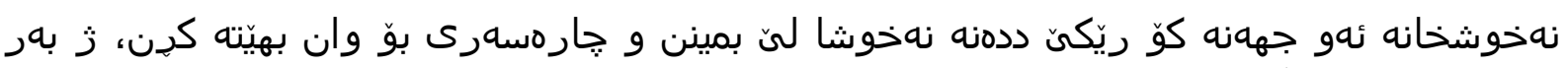

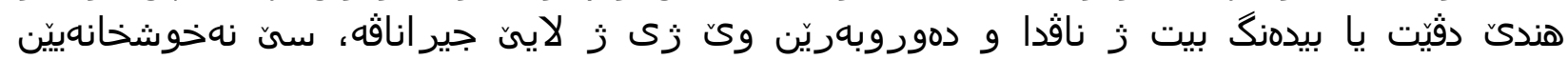

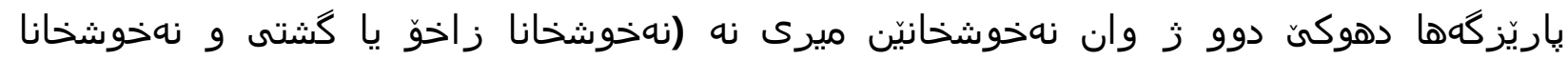

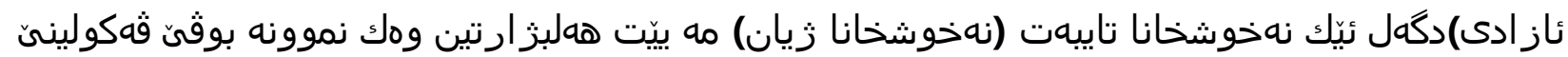

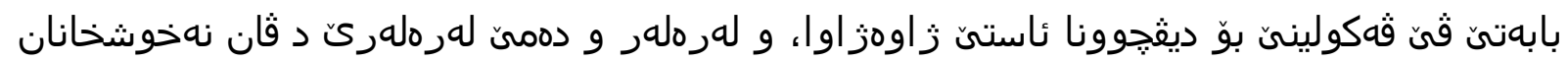

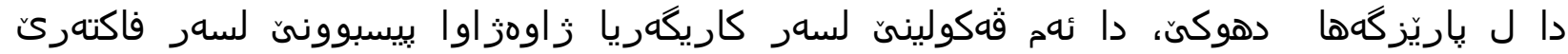

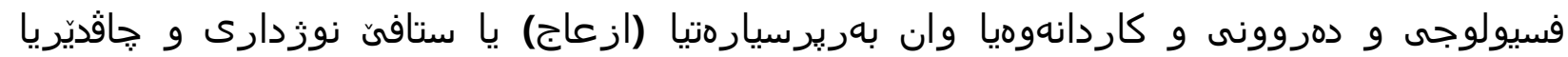

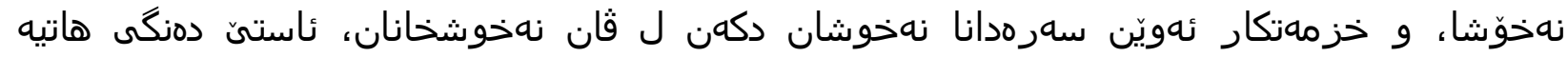

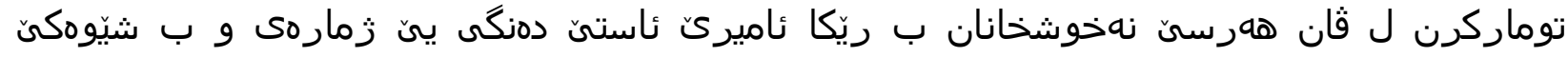

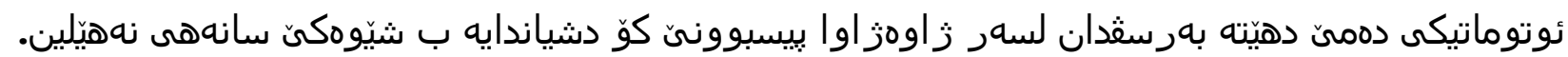

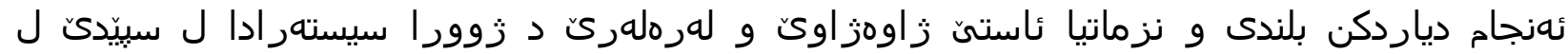

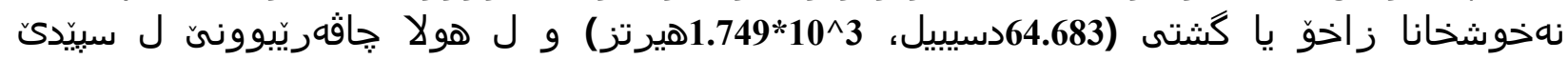

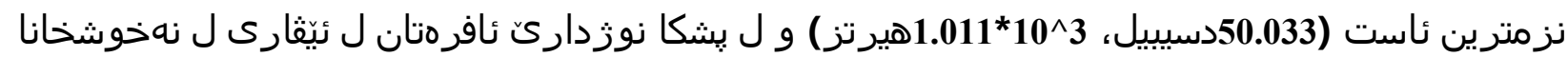




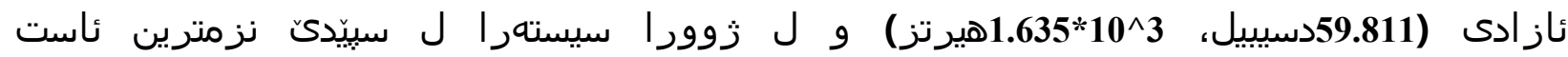
(650.838)

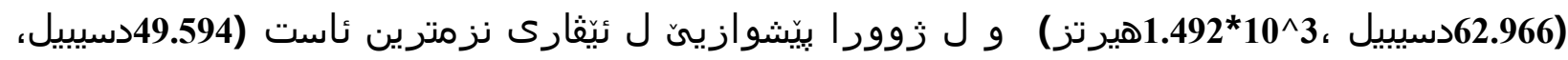

.

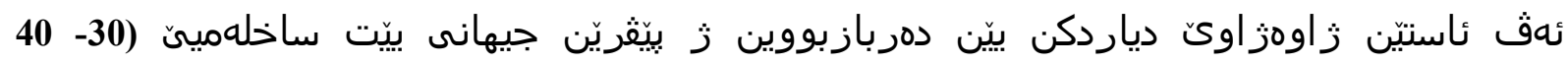

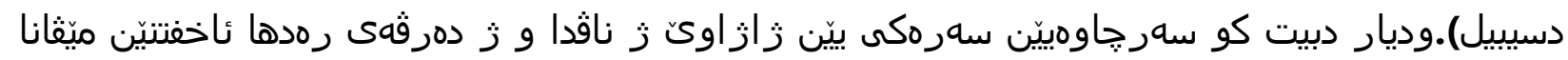

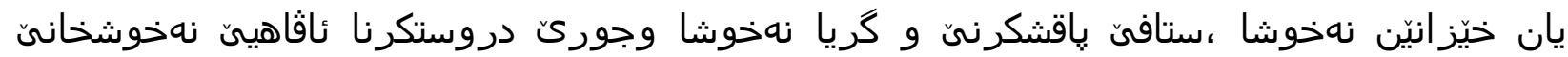
.......

الخلاصة

المستشفيات هي الاماكن التي توفر للمرضى الراحة. لذا ينبغي ان تتوفر فيها الهدوء وهي احدى عوامل الرحه.ولقد

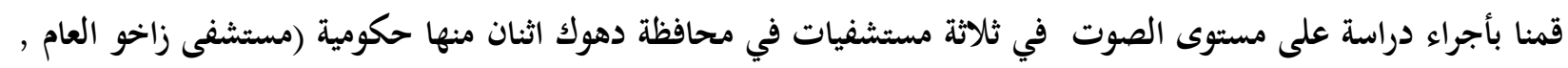

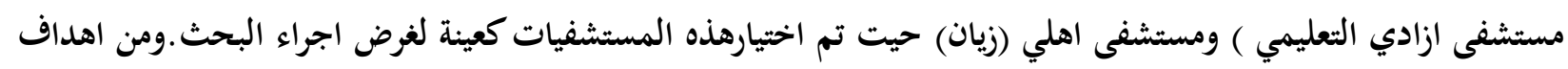

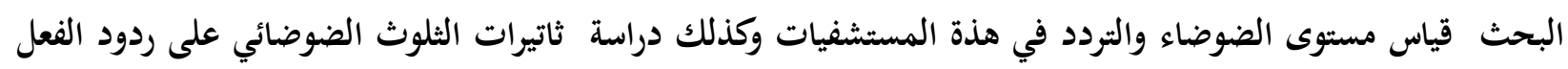
الفسيولوجية والنفسية والاستجابة لازعاج الموظفين العاملين في المجال الرعاية الطبية والمرضى والعمال والزائرين في

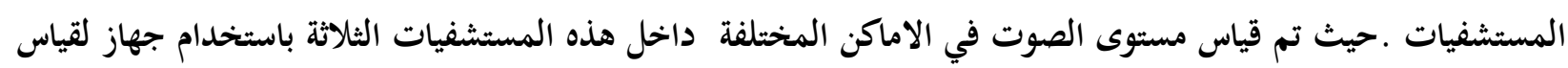

الصوت (Digital Sound Level Meter ).

حيث اظهر ت النتائج ان معدل ارتفاع وانخفاض مستوئ الضجيج والتردد في صالة الانتظار عند الصباح في مستشفى زاخو العام (64.683 dBA) وبتردد (103Hz× 749. 1) وسجلت اوطأ انخفاض لضجيج في ردهة الباطنية للاناث عند

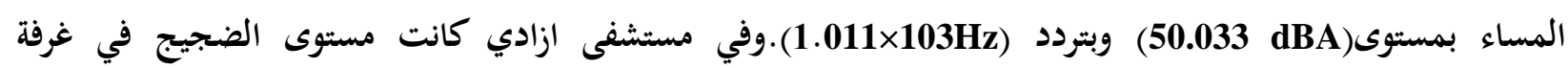
الممرضات عند الصباح بمقدار (103Hz (1035 (1.635) اما ردهة الباطنية للذكور فكانت اقل انخفاضا لضجيج عند المساء بمقار(6AA dBA × 103Hz (50.883)

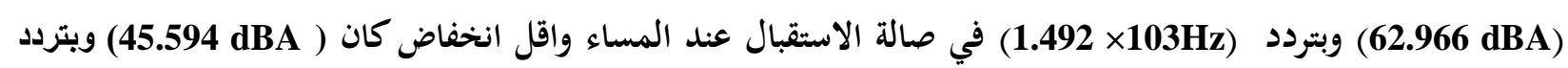
(0.77×103Hz) يشكل الثلوث الضوضائي في مستشفيات محافظة دهوك مشكلة حقيقية حيت سجلت مستويات للضوضوضاء فاقت بكثير المستويات القياسية للصوت لمنظمة الصحة العالميه (30-40dBA). واستنتج من الدراسة ان المصدر الرئيسي للضوضاء

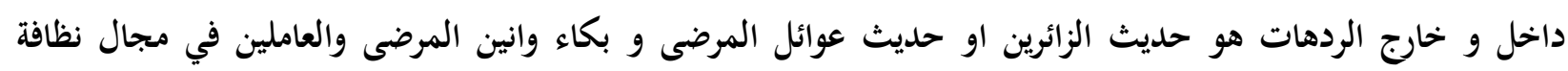

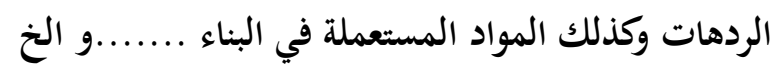

